\title{
Biologia de Anofelinos amazônicos. V. Polimorfismo cromossômico de Anopheles darlingi Root (Diptera, Culicidae)(1)
}

\author{
Wanderli Pedro Tadei ${ }^{2}$ ) \\ Joselita Maria Mendes dos. Santos ( $\left.{ }^{3}\right)$ \\ Mohammad Ghulan Rabbani $\left({ }^{4}\right)$
}

\begin{abstract}
Resumo
Foi analisado o polimorfismo cromossômico de Anopheles darlingi, cuja amostra foi obtida na Rodovia BR-174 (Manaus/Boa Vistâ). Foram descritas duas novas inversões independentes, estendendo-se para doze o número de rearranjos de A. darlingi. Três regiöes de despareamento também foram descritas, sendo uma no cromossomo $\mathrm{X}$ e duas no cromossomo 2. Ocorreu uma alta incidência de inversões no estado heterozigoto e o número médio por indivíduo foi elevado $(4,13 \pm$ 0,13 ). As freqüências elevadas e significativas de heterozigotos para a maioria das inversōes foram interpretadas como indicativas de uma adaptabilidade maior dos mesmos em relação à heterogeneidade ambiental. Os testes para associação de inversões evidenciaram a ocorrência de uma associação intracromossômica (braços $3 R$ e $3 \mathrm{~L}$ ) e quatro intercromossômicas (cromossomos $X-3$ e 2 - 3). Os dados de polimorfismo cromossômico de Anopheles darlingi corroboram a hipótese de que populações centrais da área de distribuição geográfica de uma espécie são mais polimórficas que as populaçōes marginais. As populaçōes de A. darlingi da Amazônia são altamente polimórficas quando comparadas com as populações do sul nas quais foram fixados determinados arranjos com reduzido polimorfismo.
\end{abstract}

\section{INTRODUÇÃo}

Anopheles darlingi, do subgênero Nyssorhynchus, é o principal vetor da malária humana no Brasil, sendo, praticamente, o transmissor em todo o interior do país (Rachou, 1958; Ferreira, 1964). Esta espécie apresenta uma ampia distribuição geográfica, ocorrendo desde o México até o norte da Argentina (Forattini, 1962; Kreutzer et al., 1972; Pessoa \& Martins, 1978). No Brasil, foi constatada em todos os estados brasileiros, com exceção de Santa Catarina e Rio Grande do Sul (Ferreira, 1964)

Os primeiros registros relativos ao polimorfismo cromossômico de Anopheles darlingi foram realizados por Guedes et al. (1957), Schreiber \& Guedes $(1960,1961)$. Esses autores assinalaram a ocorrência de duas inversões em um dos autossomos no estado heterozigoto, de material procedente da região de Bocaiuva (MG). Posteriormente, Kreutzer et al. (1972) realizaram um estudo mais aniplo e descreveram nove inversões independentes e um arranjo complexo. Analisaram duas populações brasileiras, uma da Amazônia e outra do sul do país, e verificaram que a população do norte é altamente polimórfica quando comparada com a população do sul. Esta última, segundo os autores, aparentemente fixou determinados arranjos com reduzido polimorfismo.

Com o objetivo de contribuir para o conhecimento do polimorfismo cromossômico de Anopheles darlingi, neste trabalho são apresentados dados relativos a uma população da Amazônia, em uma área onde a malária é endêmica.

\section{MATERIAL E MÉTODOS}

A amostra de Anopheles darlingi analisada foi obtida no Km 137 da Rodovia BR-174 (Manaus/Boa Vista), nos meses de outubro e novembro de 1976. A região caracteriza-se por uma alta incidência de casos de malária, sendo as infecções causadas por Plasmodium vivax e P. faiciparum (Ferraroni \& Hayes, 1979). É uma

(1) - Trabalho subvencionado pela FAPESP e pelo CNPq.

(2) $\rightarrow$ Universidade Estadual Paulista (UNESP), São José do Rio Preto, SP.

(3) - Instituto Nacional de Pesquisas da Amazônia, Manaus.

(4) - Em memória. Os dados de campo deste trabalho foram obtidos por este autor, cujo falecimento em 02 de fevereiro de 1977 resultou de infecção mista de Plasmodium falciparum e P. vivax. 
área de colonização recente (1973-1974) e as linhagens de $P$. falciparum apresentaram resistências às cloroquinas (Ferraroni et al., 1977) . Amostra de $A$. darlinngi da região revelaram um comportamento de resistência ao DDT (Hayes \& Charlwood, 1977).

As lâminas foram preparadas a partir de larvas de $4^{\circ}$ estádio e os cromossomos das glândulas salivares foram analisados. A técnica empregada foi a de French et al. (1962). As fêmeas coietadas na natureza foram transportadas para o laboratório e postas para desovar individualmente. Após a eclosão, as larvas oriundas de cada desova foram mantidas até o $4^{\complement}$ estádio e então utilizadas no preparo das lâminas. De cada desova foram feitas, em média, quatro lâminas. O meio de montagem da Zeiss para contraste de fase-L15 $(\mathrm{nD}=$ 1,515) foi utilizado nas preparações permanentes.

\section{RESULTADOS}

As populações de Anopheles darlingi estudadas por Kreutzer et al. (1972) eram procedentes de Manaus-Itacoatiara, Estado do Amazonas e de Araraquara, Estado de São Pauio. As nove inversões independentes, descritas por esses autores, estão distribuídas em todos os cromossomos da seguinte forma: uma no cromossomo $X$ e designada $\ln (1) 1$; três no $2 R$ e designadas $\ln (2 R) 1, \ln (2 R) 2$ e $\ln (2 R) 3$; uma no $2 \mathrm{~L}, \ln (2 \mathrm{~L}) 1$; e duas em cada um dos braços do cromossomo $3: \ln (3 R) 1, \ln (3 R) 2$ e $\ln (3 L) 1$, $\ln (3 L) 2$.

O arranjo complexo está localizado no braço 2L e é designado arranjo "Manaus" (Kreutzer et al., 1972). Em relação a este braço cromossômico, além do arranjo "Manaus" ocorre também um outro arranjo descrito pelos mesmos autores, denominado "Araraquara", que apresenta a inversão (2L) 1 no estado homozigoto, cujos limites são 22A-21A. O arranjo "Manaus" contém, além da inversão (2L)1, uma nova inversão, designada $\ln (2 \mathrm{~L}) 2$, a qual é superposta em relação à primeira, abrangendo as regiões $22 \mathrm{~B}-22 \mathrm{~A}$ em $\ln (2 \mathrm{~L}) 1$ e as regiões 21B-20A forå dos limites dessa inversão.

INo presente trabalho, a análise da amostra da população do Km 137 da BR-174 revelou duas novas inversões e três regiões de despareamento (Fig. 1). Uma inversão está localizada no cromossomo $2 R$, na região proximal e a outra no cromossomo $3 R$, entre as inversões $(3 R) 1$ e $(3 R) 2$. Uma das regiões de despareamento está localizada na extremidade proximal do cromossomo $\mathrm{X}$; a segunda na extremidade distal do $2 \mathrm{R}$ e a terceira no início do último terço na extremidade proximal do cromossomo 2L. Na determinação dos limites das duas inversões e das regiōes de despareamento foi utilizado o mapa cromossômico proposto por Kreutzer et al. (1972), o qual é considerado como arranjo padrão tendo sido preparado pelos autores a partir de uma população de Manaus.

A inversão localizada no braço $2 \mathrm{R}$, logo após a in (2R)3, próximo à região centromérica, abrange desde aproximadamente $2 / 3$ da região $14 \mathrm{~A}$ até a região mediana de $14 \mathrm{C}$. A inversão localizada no $3 \mathrm{R}$ abrange uma parte da região $32 \mathrm{~B}$ e a região $33 \mathrm{~A}$. As inversões foram designadas $2 R d$ e $3 R c$, respectivamente, seguindo-se a denominação usualmente utilizada em Drosophila, particularmente por Wassermann (1963), Carson et al. (1967), Bicudo (1973) e para Anopheies stephensi e A. superpictus por Coluzzi et ai. (1973). As inversões descritas por Kreutzer et al. também foram redenominadas seguindo-se esta mesma nomenclatura. $\mathrm{Na}$ tabela 1 constam todas as inversões de $A$. darlingi descritas, com as denominaçōes anteriores e as adotadas para este trabalho. No diagrama da figura 2 , as inversões estão representadas segundo as delimitaçōes feitas por Kreutzer et al., com exceção de 2Rd e 3Rc. cujos limites foram determinados neste trabaIho.

As três regiões de despareamento também estão representadas na fig. 2 , sendo quee a primeira, localizada no cromossomo $\mathrm{X}$, abrange descle a região mediana de $4 B$ até a parte final de 5B. A segunda, situada na extremidade distal do braço $R$ do cromosso 2, envolve toda a região 6 e parte de $7 \mathrm{~A}$. A terceira região localizada no cromossomo 2L, compreende parte da $18 \mathrm{~A}$ e inteiramente a $18 \mathrm{~B}$.

Na taibela 2 são apresentadas as freqüências de fêmeas que produziram descendentes com os despareamentos. É apresentada tam- 
bém a frequiência com que os despareamentos foram detectados entre os descendentes de cada fêmea. O fato de terem sido constatados entre os descendentes de cada fêmea indivíduos com pareamento normal e indivíduos com despareamento para as regiões consideradas, torna-se evidente que na população ocorrem as duas formas cromossônicas. Os dados da tabela 2 indicam que foram mais freqüentes as fêmeas que produziram descendentes com despareamento no cromossomo $\mathrm{X}$ e $2 \mathrm{~L}$, representando $41 \%$ e $52 \%$ respectivamente, do total de fêmeas analisadas em cada caso.

Em relação ao cromossomo X, foram computadas apenas as larvas fêmeas. Foram analisados 50 indivíduos, descendentes de 13 fê-

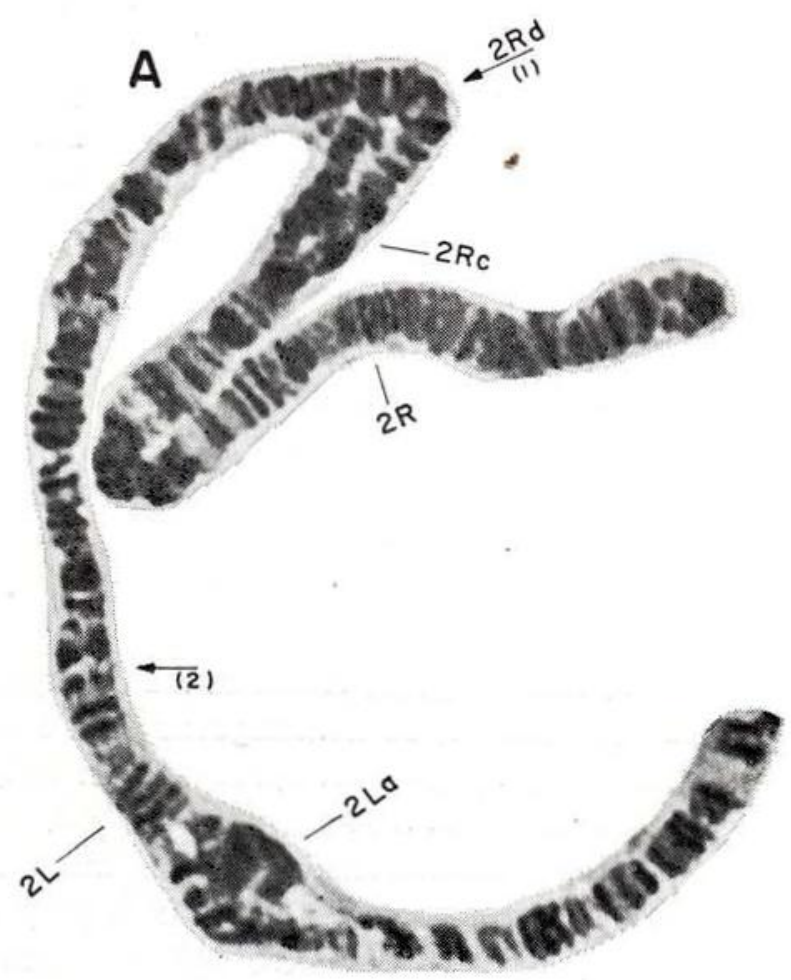

B

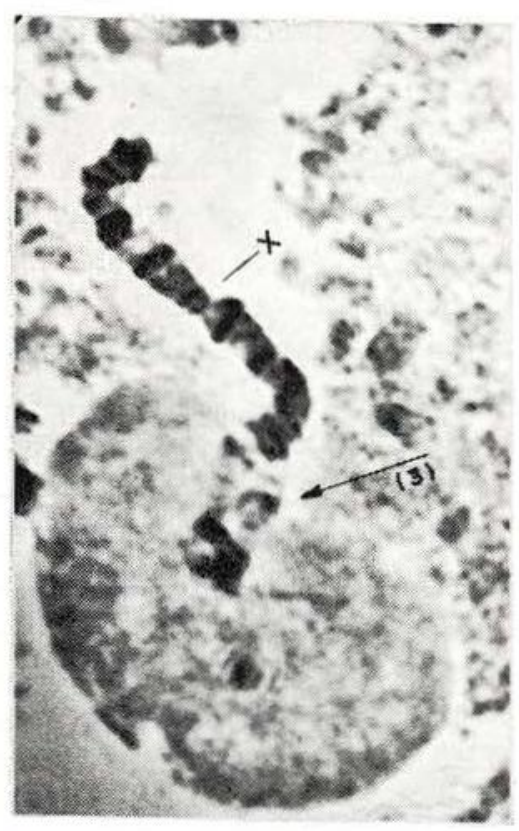

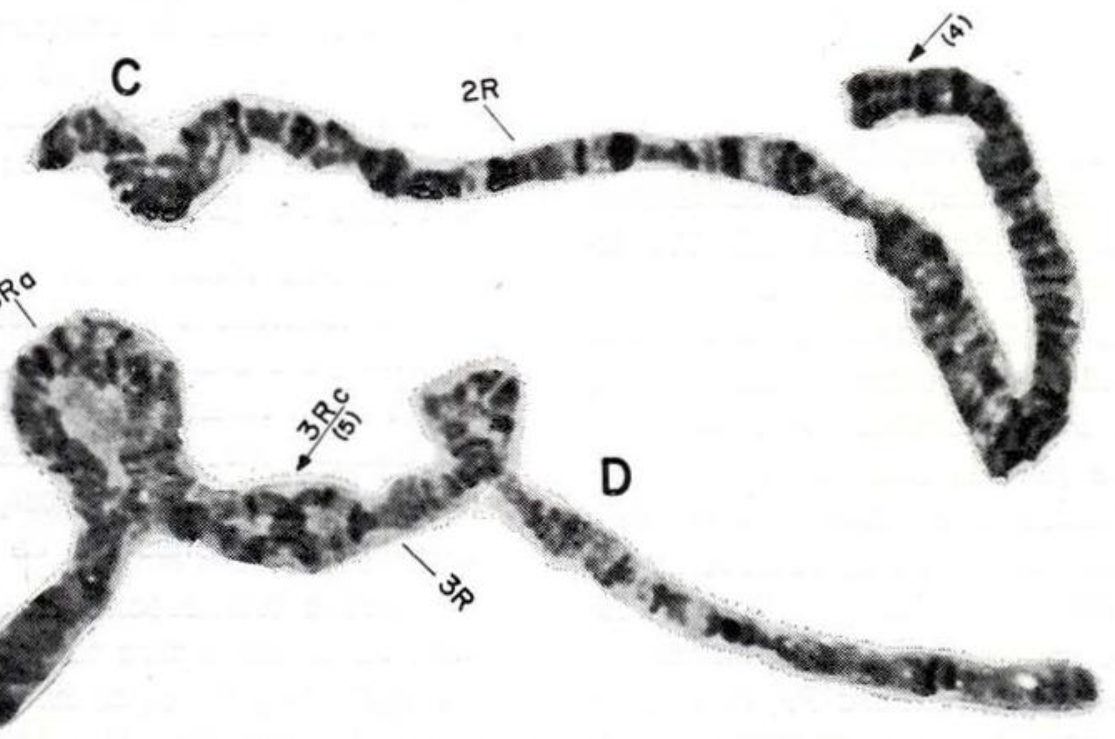

Fig. 1 C $\mathbf{A}$ - Inversão $2 \mathrm{Rd}$ do braço $2 \mathrm{R}$ ( seta $_{1}$ ) e região de despareamento do braço $2 \mathrm{~L}$ (seta ) $^{\text {B }}$ - Despareamento da região proximal do cromossomo $\mathrm{X}\left(\right.$ seta $\left._{3}\right)$ e associação ao nucléolo, indicando que este cromossomo é organizador do nucléolo. C - Despareamento da região distal do braço $2 \mathrm{~L}\left(\right.$ seta $_{4}$ ). D - Inversão $3 R$ c do braço $3 R$ (seta ${ }_{5}$ ). 
meas, e $52 \%$ apresentaram despareamento. Para o cromosscmo 2R, o número de indivíduos analisadios foi de 32 , descendentes de 7 fêmeas, e exatamente $50 \%$ mostrararn o despareamento. Quanto ao cromossomo 2L, foi analisado o maior número de indivíduos - 73 , descendentes de 16 fêmeas, e $40 \%$ apresentaram despareamento.

A análise da constituição cromossômica dos 32 fêmeas estudadas foi realizada reconhecendo-se os homozigotos para o arranjo padrão (PP), homozigotos para o arranjo das inversões (II) e heterozigotos (PI). Os resultados mostraram que nenhuma das fêmeas analizadas produziu descendentes homozigotos para os três pares de cromossomos simultaneamente. $\mathrm{Na}$ tabela 3 , são apresentadas as freqüências de fêmeas que produziram descendentes homozigotos e fêmeas que produziram descendentes homo e heterozigotos para cada uma das inversões nos três pares de cromossomos. Em uma primeira observação, verificase que ocorre elevada incidência de fêmeas que produziram descendentes homo e heterozigotos para as diferentes inversöes. Os valores foram especialmente altos para $2 \mathrm{Rb}, 2 \mathrm{Rc}, 2 \mathrm{Lb}$, $3 \mathrm{Rb}$ e $3 \mathrm{La}$. Resultados opostos foram verificados para a inversão $2 R a$, cuja freqüência de homo e heterozigotos foi apenas de $8 \%$. Para o cromossomo $X$, também foi elevada a freqüência de homozigotos $(75 \%)$. Valores intermediários cocorreram para as inversões $3 \mathrm{Ra}$ e 3Lb.

Para a análise das freqüências das inversões, todos os descendentes das 32 fêmeas estudiadas foram reunidos, totalizando 118 indivíduos. $\mathrm{Na}$ tabela 4 constam as frecuïências observadas para os três pares de cromossomos, considerando-se os arranjos PP. PI e II. Os dados para o cromossomo $X$ referem-se apenas às larvas fêmeas analisadas e as freqüências verificadas são coincidentes com aquelas observadas na tabela 3 . Fêmeas homozigotas para o arranjo da inversão $\mathrm{Xa}$ não foram detectadas. Em relação ao cromossomo $2 \mathrm{R}$, as fórmulas cromossômicas PP, PI e II foram observadas para as inversões $2 \mathrm{Ra}$ e $2 \mathrm{Rc}$. Indivíduos homozigotos $2 \mathrm{Rb}$ não foram observados. Homozigotos 2 Ra para o arranjo padrão (PP) foram os mais freqüentes $(85 \%)$. Para
TABELA 1 - Inversöes de Anopheles darlingi com as denominações de Kreutzer et al. (1972) e as adotadas neste trabalho.

\begin{tabular}{|c|c|c|}
\hline \multirow{2}{*}{ Cromossomo } & \multicolumn{2}{|c|}{ Inversão } \\
\hline & $\begin{array}{c}\text { denominação } \\
\text { de Kreutzer et al. }\end{array}$ & $\begin{array}{l}\text { denominação } \\
\text { neste trabalho }\end{array}$ \\
\hline$x$ & $\ln (1) 1$ & $\mathrm{Xa}$ \\
\hline \multirow[t]{4}{*}{$2 R$} & In $(2 R) 1$ & $2 \mathrm{Ra}$ \\
\hline & In $(2 R) 2$ & $2 \mathrm{Rb}$ \\
\hline & In $(2 R) 3$ & $2 R c$ \\
\hline & - & 2Rd \\
\hline \multirow[t]{2}{*}{$2 \mathrm{~L}$} & $\ln (2 \mathrm{~L}) 1$ & 2La \\
\hline & $\begin{array}{l}\text { Arranjo } \\
\text { "Manaus" }\end{array}$ & $2 \mathrm{Lb}$ \\
\hline \multirow[t]{3}{*}{$3 R$} & In $(3 R) 1$ & $3 R a$ \\
\hline & In $(3 R) 2$ & $3 R b$ \\
\hline & - & $3 R c$ \\
\hline \multirow[t]{2}{*}{$3 L$} & $\ln (3 L) 1$ & 3La \\
\hline & $\ln (3 L) 2$ & $3 \mathrm{Lb}$ \\
\hline
\end{tabular}

$2 \mathrm{Rb}$, os heterozigotos foram os mais freqüentes $(63 \%)$; contudo, os homozigotos para o arranjo padrão (PP) também apresentaram freqüências elevadas $(37 \%)$. No caso de 2 Rc, os heterozigotos mostraram os níveis mais altos $(84 \%)$; os homozigotos para o arranjo padrão (PP) e para a inversão (II) apresentaram freqüências baixas ( $13 \%$ e $3 \%$, respectivamente). A inversão $2 R d$ foi computada apenas no estado heterozigoto porque os homozigotos PP e II não foram diferenciados. Essa inversão ocorreu em níveis próximos daqueles observados para Xa $(24 \%)$.

As três fórmulas cromossômicas também foram verificadas para $2 \mathrm{Lb}$. Indivíduos homozigotos para o arranjo padrão (PP) e heterozigotos (PI) foram os mais freqüentes, porém os últimos apresentaram os níveis mais altos $(63 \%)$. Indivíduos homozigotos para $2 \mathrm{Lb}$ representaram apenas $8 \%$ da amostra analisada.

Para o cromossomo 3 , os três arranjos foram observados para todas as inversões, com exceção de $3 R b$, cujos homozigotos para o arranjo da inversão (II) não foram detectados. A inversão $3 R$ c também foi computada apenas no estadio heterozigoto e na freqüência de $18 \%$. Valores aproximadamente iguais foram obser- 

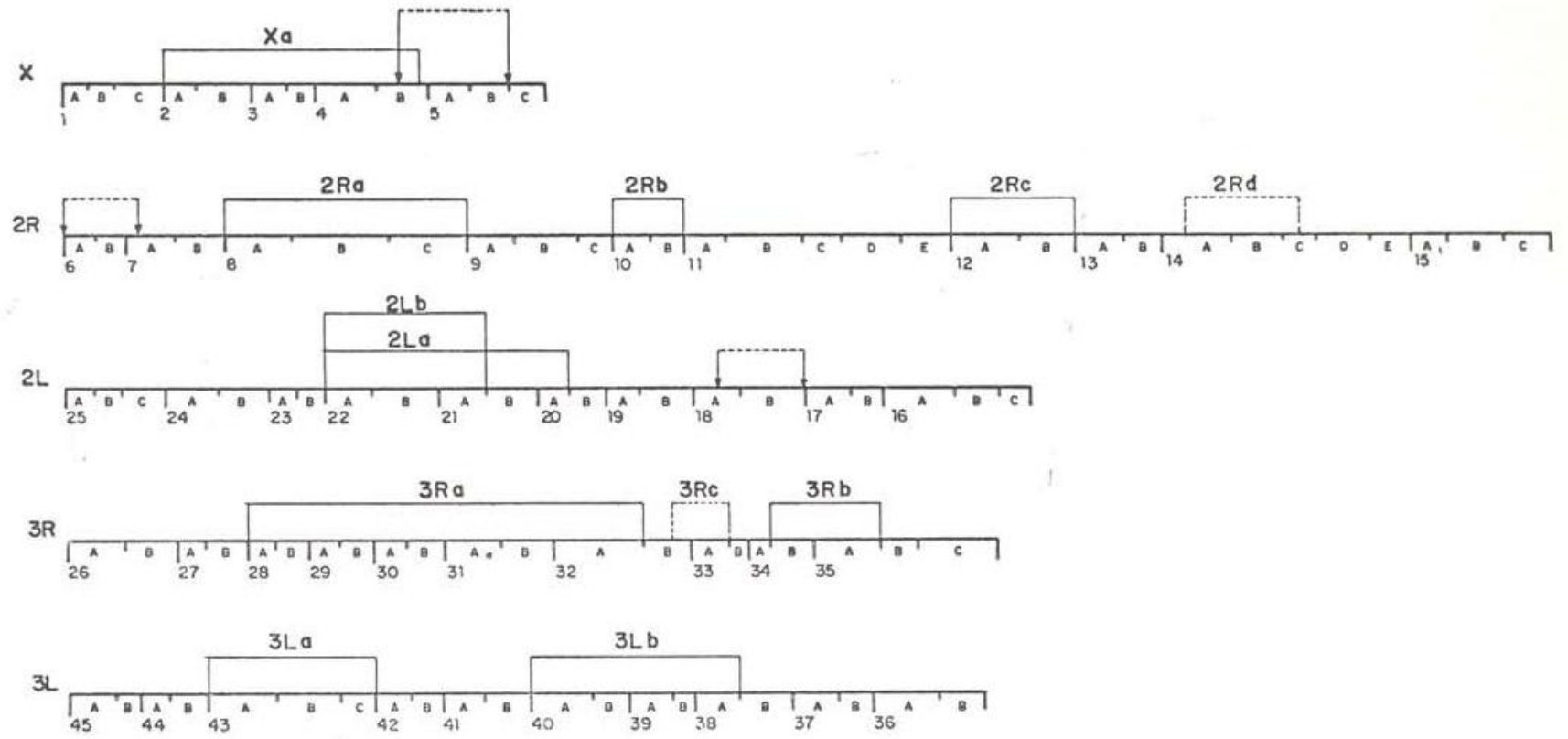

Fig. 2 - Diagrama das inversões e regiões de despareamento de Anopheles darlingi. - inversões pre-

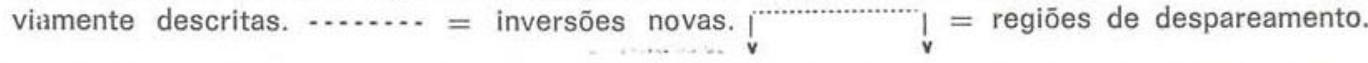

vados para os arranjos PP e PI da inversão $3 R a$ (respectivamente, $49 \%$ e $48 \%$ ). Para $3 \mathrm{Rb}$, os valores para os arranjos PP e PI também foram próximos, porém com divergência maior $(46 \%$ e $54 \%$ ) . Para o braço $3 \mathrm{~L}$, as freqüências observadas dos arranjos PP e PI para $3 \mathrm{La} \mathrm{e} 3 \mathrm{Lb}$ foram opostos para as duas inversões. Enquanto na primeira foi mais freqüente o arranjo PI $(60 \%)$, na segunda foi o arranjo PP $(65 \%)$.

A observação dos dados da tabela 4 possibilita visualizar que a classe dos heterozigotos (PI) para as diferentes inversões, ocorreu em frequêencias superiores a $50 \%$ em 5 dos 9 casos analisados, nos quais os três arranjos foram estudados. Possibilita visualizar também que a classe dos homozigotos PP é, freqüentemente, muitas vezes maior que a dos homozigotos II. Na tabela 5 são apresentados os desvios entre as fiequiências observadas e esperadas segundo o teorema de Hardy-Weinberg, calculados a partir dos dados constantes na tabela 4, para os três arranjos de todas as inversões. O qui-quadrado não foi calculado no caso das inversões $\mathrm{Xa}, 2 \mathrm{Ra}$ e $3 \mathrm{Lb}$, pois existem freqüências esperadas abaixo de 5 . No entanto, por inspeção dos dados, torna-se evidente que não existem diferenças estatísticas entre o observado e o esperado para as inversões $\mathrm{Xa}$ e $3 \mathrm{Lb}$. Não se pode tirar conclusões em rela- ção à inversão 2Ra. Para as demais inversões, os desvios foram significativos e os valores observados para a classe dos heterczigotos foram maiores que os esperados, segundo o equilibrio de Hardy-Weinberg. Alguma mortaiidade diferencial favorecendo os heterozigotos e discriminando contra os homozigotos deve ocorrer na população.

As inversões dos três pares de cromossomos foram testadas quanto à ocorrência de associação, por meio do qui-quadrado. Para análise, uma inversão foi considerada em relaçãci a outra e os testes foram intra e intercromossômicos. No primeiro caso, foram verificadas as inversões dentro de cada braço cromossômico e entre os dois braços de cada cromossomo e no segundo caso, as inversões de um cromossomo em relação às de outro. Como a análise cromossômica foi desenvolvida reconhecendo-se os homozigotos para o arranjo padrão, para o arranjo da inversão e os heterozigotos, em cada teste de associação era possível verificar nove combinações. No entanto, como a classe dos homozigctos para o arranjo da inversão mostrou sempre freqüências baixas e foi mesmo inexistente em alguns casos (tabela 4), os testes foram realizados considerando-se apenas as classes dos homozigotos para o arranjo padrão e heterozigotos. 
Desto forma, apenas quatro combinações foram testadas em cada caso, e uma tabela de contingência $2 \times 2$ foi utilizada.

$\mathrm{Na}$ tabela 6 constam os dados relativos aos testes de associação intracromossômico. Considerando as inversões dentro de cada braço crornossômico, foram possíveis quatro combi- nações no braço $2 R$ e uma combinação para cada um dos braços do cromossomo 3. Os desvios não foram significativos para o cro mossomo 2 nem para o 3 . Entre as inversões dos dois braços de cada cromossomo, de sete combinações possiveis, uma apresentou o valor de qui-quadrado significativo $-3 \mathrm{Rb} \times 3 \mathrm{Lb}$

TABELA 2 - Freqüência de fêmeas que produziram descendentes com despareamento nos cromossomos $X$ e 2 e freqüência do despareamento entre os descendentes de cada fêmea. ( )=percentagem.

\begin{tabular}{|c|c|c|c|c|c|}
\hline \multirow[b]{2}{*}{ Cromossomo } & \multirow{2}{*}{$\begin{array}{l}\text { total de fêmeas } \\
\text { analisadas }\end{array}$} & \multirow{2}{*}{$\begin{array}{l}\text { fêmeas que produ- } \\
\text { ziram descendentes } \\
\text { com despareamento }\end{array}$} & \multirow{2}{*}{$\begin{array}{l}\text { descendentes } \\
\text { analisados em } \\
\text { cada caso }\end{array}$} & \multicolumn{2}{|c|}{ descendentes } \\
\hline & & & & $\begin{array}{c}\text { pareamento } \\
\text { normal }\end{array}$ & despareamento \\
\hline \multirow[t]{14}{*}{$x$} & 32 & $13(41)$ & 3 & 1 & 2 \\
\hline & & & 6 & 1 & 5 \\
\hline & & & 2 & 0 & 2 \\
\hline & & & 5 & 3 & 2 \\
\hline & & & 3 & 1 & 2 \\
\hline & & & 5 & 4 & 1 \\
\hline & & & 6 & 0 & 6 \\
\hline & & & 4 & 3 & 1 \\
\hline & & & 5 & 4 & 1 \\
\hline & & & 2 & 1 & 1 \\
\hline & & & 4 & 3 & 1 \\
\hline & & & 4 & 3 & 1 \\
\hline & & & 1 & 0 & 1 \\
\hline & & & total 50 & $24(48)$ & $26(52)$ \\
\hline \multirow[t]{8}{*}{$2 \mathrm{R}$} & 29 & $7(24)$ & 5 & 1 & 4 \\
\hline & & & 5 & 3 & 2 \\
\hline & & & 4 & 3 & 1 \\
\hline & & & 5 & 4 & 1 \\
\hline & & & 4 & 2 & 2 \\
\hline & & & 5 & 0 & 5 \\
\hline & & & 4 & 3 & 1 \\
\hline & & & total 32 & $16(50)$ & $16(50)$ \\
\hline \multirow[t]{14}{*}{ 2L. } & 31 & $16(52)$ & 4 & 2 & 2 \\
\hline & & & 5 & 4 & 1 \\
\hline & & & 5 & 4 & 1 \\
\hline & & & 3 & 2 & 1 \\
\hline & & & 7 & 4 & 3 \\
\hline & & & 5 & 2 & 3 \\
\hline & & & 5 & 4 & 1 \\
\hline & & & 5 & 4 & 1 \\
\hline & & & 5 & 3 & 2 \\
\hline & & & 4 & 3 & 1 \\
\hline & & & 4 & 3 & 1 \\
\hline & & & 4 & 2 & 2 \\
\hline & . & & 3 & 2 & 1 \\
\hline & & & 5 & 3 & 2 \\
\hline \multirow[t]{3}{*}{ - } & & & 5 & 2 & 3 \\
\hline & & & 4 & 0 & 4 \\
\hline & & & total 73 & $44(60)$ & $29(40)$ \\
\hline
\end{tabular}


TABELA 3 - Fraqüências de fêmeas que produziram descendentes homozigotos, e homo e heterozigotos para cada uma das inversões dos três pares de cromossomos.

\begin{tabular}{|c|c|c|c|c|c|c|c|}
\hline \multirow{2}{*}{ Cromossomo } & \multirow{2}{*}{$\begin{array}{c}\text { Número de fêmeas } \\
\text { analisadas }\end{array}$} & \multicolumn{3}{|c|}{$\begin{array}{l}\text { Homozigoto \% } \\
\text { inversão }\end{array}$} & \multicolumn{3}{|c|}{$\begin{array}{c}\text { Homo e Heterozigoto } \\
\text { inversão }\end{array}$} \\
\hline & & a & b & c & a & $b$ & c \\
\hline$x$ & 32 & 75 & - & - & 25 & - & - \\
\hline $2 R$ & 29 & 92 & 28 & 8 & 8 & 72 & 92 \\
\hline $2 \mathrm{~L}$ & 31 & - & 16 & - & - & 84 & - \\
\hline $3 R$ & 27 & 37 & 30 & - & 63 & 70 & - \\
\hline $3 \mathrm{~L}$ & 30 & 17 & 43 & - & 83 & 57 & - \\
\hline
\end{tabular}

$\left(X_{1}^{2}=5,557 ; P<0,05\right)$. Para as combinações $2 \mathrm{Ra} \times 2 \mathrm{Rb}$ (deritro de cada braço cromossômico) e $2 \mathrm{Ra} \times 2 \mathrm{Lb}$ (entre os braços de cada cromossomo) o qui-quadrado não foi calculado pois existem freqüências esperadas abaixo de 5. Entretanto, os valores observados e esperados são próximos, tornando evidente que não existem diferenças significativas. Porém em relação a $2 \mathrm{Ra} \times 2 \mathrm{Rc}$ os dados não permitem conclusões

Os testes para combinações intercromossômicas (tabela 7) revelaram que a grande maioria das inversões se distribuem ao acaso, como ocorreu também para as combinaçöes intracromossômicas. De 24 combinações testadas no total, quatro apresentaram valores de qui-quadrado significativo. Para os testes en- tre os cromossomos $\mathrm{X}$ e 2 não ocorreram combinações significativas. Das quatro combinações possíveis entre os cromossomos $X$ e 3 . duas apresentaram desvios significativos $\mathrm{Xa} \times 3 \mathrm{Rb}\left(\mathrm{X}^{2}=4,549 ; \mathrm{P}<0,05\right)$ e $\mathrm{Xa} \times 3 \mathrm{lb}$ $\left(X_{1}^{2}=4,933 ; P<0,05\right)$. Os testes entre as 16 combinações para os cromossomos 2 e 3 evidenciaram que $2 \mathrm{Rc} \times 3 \mathrm{Ra}$ e $2 \mathrm{Lb} \times 3 \mathrm{Ra}$ não se distribuem ao acaso e os valores de quiquadrado foram, respectivamente, 5.135; $\mathrm{P}<$ 0,05 e 5,754; $P<0,05$. Pelas mesmas razōes já expostas quando da descrição da tabela 6 , o qui-quadrado não foi calculado para as combinações Xa $\times 2 \mathrm{Ra}$, Xa $\times 2 \mathrm{Rc}, 2 \mathrm{Ra} \times 3 \mathrm{Ra}, 2 \mathrm{Ra} \times$ $3 \mathrm{Rb}, 2 \mathrm{Ra} \times 3 \mathrm{La}, 2 \mathrm{Ra} \times 3 \mathrm{Lb}$ e $2 \mathrm{Rc} \times 3 \mathrm{Lb}$. Contudo, a observação dos dados possibilita verificar que não existem desvios estatisticamente sig-

TABELA 4 - Freqüências dos arranjos na descendência das fêmeas analisadas. $P=$ arranjo padrão; $I=$ arranjo da inversão.

\begin{tabular}{|c|c|c|c|c|c|}
\hline \multirow{2}{*}{ Cromossomo } & \multirow{2}{*}{ Inversão } & \multirow{2}{*}{$\begin{array}{l}\text { Número de descendentes } \\
\text { analisados }\end{array}$} & \multicolumn{3}{|c|}{ Arranjos observados \% } \\
\hline & & & PP & $\mathrm{PI}$ & II \\
\hline$x$ & $\mathrm{Xa}$ & 77 & 75 & 25 & 0 \\
\hline \multirow[t]{4}{*}{$2 \mathrm{R}$} & $2 \mathrm{Ra}$ & 94 & 85 & 5 & 10 \\
\hline & $2 R b$ & 98 & 37 & 63 & 0 \\
\hline & $2 R c$ & 105 & 13 & 84 & 3 \\
\hline & 2Rd & 105 & - & 24 & - \\
\hline $2 \mathrm{~L}$ & $2 \mathrm{Lb}$ & 118 & 29 & 63 & 8 \\
\hline \multirow[t]{3}{*}{$3 R$} & $3 R a$ & 111 & 49 & 48 & 3 \\
\hline & $3 R b$ & 89 & 46 & 54 & 0 \\
\hline & 3Rc & 89 & - & 18 & - \\
\hline \multirow[t]{2}{*}{ 3L } & 3La & 111 & 39 & 60 & 1 \\
\hline & 3Lb & 100 & 65 & 32 & 3 \\
\hline
\end{tabular}


TABELA 5 - Freqüências observadas e esperadas dos arranjos e as respectivas diferenças e valores de qui-quadrado. $\mathbf{P}=$ arranjo padrão; $\mathbf{I}=$ arranjo da inversão.

\begin{tabular}{|c|c|c|c|c|c|c|}
\hline \multirow{2}{*}{ Cromossomo } & \multirow{2}{*}{ inversão } & & \multicolumn{3}{|c|}{ Arranjos } & \multirow{2}{*}{$x_{1}^{2}$} \\
\hline & & & PP & PI & II & \\
\hline \multirow[t]{3}{*}{$x$} & Xa & obs. & 59 & 19 & 0 & \\
\hline & & esp. & 59,2 & 16,6 & 1,2 & \\
\hline & & dif. & $-1,2$ & $+2,4$ & $-1,2$ & + \\
\hline \multirow[t]{9}{*}{$2 R$} & $2 \mathrm{Ra}$ & obs. & 79 & 5 & 10 & \\
\hline & & esp. & 70,6 & 21,7 & 1,7 & \\
\hline & & dif. & $+8,4$ & $-16,7$ & $+8,3$ & + \\
\hline & $2 R b$ & obs. & 36 & 62 & 0 & \\
\hline & & esp. & 45,8 & 42,4 & 9,8 & \\
\hline & & dif. & $-9,8$ & $+19,6$ & $-9,8$ & $20,96 * * *$ \\
\hline & $2 R c$ & obs. & 14 & 88 & 3 & \\
\hline & & esp. & 32,0 & 51,9 & 21.1 & \\
\hline & & dif. & $-18,0$ & $+36,1$ & $-18,1$ & $50,76 * *$ * \\
\hline \multirow[t]{3}{*}{$2 \mathrm{~L}$} & $2 \mathrm{Lb}$ & obs. & 34 & 75 & 9 & \\
\hline & & esp. & 43,3 & 56,4 & 18,3 & \\
\hline & & dif. & $-9,3$ & $+18,6$ & $-9,3$ & $12,86 * \cdots$ \\
\hline \multirow[t]{6}{*}{$3 R$} & 3Ra & obs. & 55 & 53 & 3 & \\
\hline & & esp. & 59,8 & 43,3 & 7,9 & \\
\hline & & dif. & $-4,8$ & $+9,7$ & $-4,9$ & $5,60^{\text {* }}$ \\
\hline & $3 R b$ & obs. & 41 & 48 & 0 & \\
\hline & & esp. & 47,4 & 35,1 & 6,5 & \\
\hline & & dif. & $-6,4$ & $+12,9$ & $-6,5$ & $12,10^{* \ldots \circ}$ \\
\hline \multirow[t]{6}{*}{$3 L$} & 3La & obs. & 44 & 66 & 1 & \\
\hline & & esp. & 53,5 & 47,1 & 10,4 & \\
\hline & & dif. & $-9,5$ & $+18,9$ & $-9,4$ & 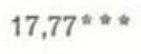 \\
\hline & $3 \mathrm{Lb}$ & obs. & 65 & 32 & 3 & \\
\hline & & esp. & 65,6 & 30,8 & 3,6 & \\
\hline & & dif. & $-0,6$ & $+1,2$ & $-0,6$ & + \\
\hline
\end{tabular}

* $=\mathrm{P}<0,05 ; \cdots=\mathrm{P}<0,005 ;+=$ qui-quadrado não calculado.

nificativos para as cinco últimas combinações. 0 mesmo não se estende às duas primeiras. cujos dados não possibilitam conclusões.

Nas tabelas 8 e 9 são apresentados dados sobre testes de associaçäo envolvendo as três regiões de despareamento. Na primeira são apresentados os resultados sobre as associações entre as regiões de despareamento e as inversões de cada braço cromossômico, e na segunda entre as regiões de despareamento do cromossomo $X$ e 2 . Em relação à tabela 8 , os homozigotos para o arranjo das inversões também não foram considerados nas combinações, como wocorreu para os dados das tabelas 6 e 7. De cinco combinações possíveis, o quiquadrado foi calculado para três e não foi sig- nificativo em nenhuma delas. Para $2 \mathrm{Ra}$ e $2 \mathrm{Rc}$, a observação dos dados também mostra que não existem diferenças significativas. Nas combinaçöes entre as regiões de despareamento (tabela 9) também não ocorrem desvios significátivos. Embora os valores de qui-quadrade não tenhsm sido calculados, os observados e os esperados sãc próximos em todas as combınaçöes.

\section{DISCUSSÃo}

Populações naturais de Anopheles freqüentemcnte apresentam polimorfismo cromossômico de inversões. Estudos intensivos em cromossomos politênicos de glândulas salivares 
e de células nutritivas de ovários possibilitaram evidenciar espécies com elevado polimorfismo cromossômico e espécies moderadamente polimórficas. Espécies monomórficas também têm sido detectadas (White, 1974; Kitzmiller, 1976). Anopheles darlingi, analisada no presente trabalho, está incluída entre as primeiras e apresenta 10 rearranjos resultantes de nove inversões independentes e duas possivelmente superpostas (Kreutzer et al., 1972) . A descrição de duas novas inversões, a partir da análise da população do $\mathrm{Km} 137$, possibilitou elevar para doze o número de rearranjos de $A$. darlingi, corroborando assim os dados existentes na literatura de que a espécie é altamente polimórfica. Anopheles gambiae espécie $B$ da África também é considerada espé- cie de elevado polimorfismo e apresenta doze inversões distintas. Anopheles messeae apresenta um número mais elevado de inversões tendo sido descritas 27 diferentes inversões autossômicas em amostras procedentes de três localidades da Bulgária (Kitzmiller, 1976).

As inversões de Anopheles darlingi distribuem-se por todos os cromossomos, não havendo, de acordo, com o teste de qui-quadrado que realizamos, ocorrência preferencial em qualquer um dos cromossomos ou mesmo em qualquer um dos braços dos cromossomos. O braço $2 R$, sendo o mais longo do lote, apresenta o maior número de inversões. O mesmo fenômeno também foi observado para algumas espécies de Drosophila, nas quais as inversões distribuem-se entre os cromossomos

TABELA 6 - Associação de inversões: análise intracromossômica de cada braço (bloco superior) e entre os dois braços de cada cromossomo (bloco inferior). $\mathrm{P}=$ homozigoto para 0 arranjo padrão; $1=$ homozigoto para a inversão; $\mathbf{H}=$ heterozigoto.

\begin{tabular}{|c|c|c|c|c|c|c|c|c|}
\hline Cromossomo & Inversőes & $\begin{array}{c}\text { Larvas } \\
\text { computadas }\end{array}$ & & $P \times P$ & $\mathrm{P} \times \mathrm{H}$ & $H \times P$ & $\mathrm{H} \times \mathrm{H}$ & $x_{1}^{2}$ \\
\hline \multirow[t]{6}{*}{$2 \mathrm{R}$} & $2 \mathrm{Ra} \times 2 \mathrm{Rb}$ & 82 & obs. & 33 & 45 & 3 & 1 & \\
\hline & & & esp. & 34,24 & 43,76 & 1,76 & 2,24 & + \\
\hline & $2 R a \times 2 R c$ & 83 & obs. & 9 & 70 & 3 & 1 & \\
\hline & & & esp. & 11,42 & 67,58 & 0,58 & 3,42 & + \\
\hline & $2 R b \times 2 R c$ & 95 & obs. & 6 & 30 & 5 & 54 & \\
\hline & & & esp. & 4,17 & 31,83 & 6,83 & 52,17 & 1,463 \\
\hline \multirow[t]{2}{*}{$3 R$} & $3 R a \times 3 R b$ & 84 & obs. & 21 & 28 & 19 & 16 & \\
\hline & & & esp. & 23,33 & 25,67 & 16,67 & 18,33 & 1,066 \\
\hline \multirow[t]{2}{*}{$3 \mathrm{~L}$} & $3 \mathrm{La} \times 3 \mathrm{Lb}$ & 95 & obs. & 32 & 9 & 33 & 21 & \\
\hline & & & esp. & 28,05 & 12,95 & 36,95 & 17,05 & 3,098 \\
\hline \multirow[t]{6}{*}{2} & $2 \mathrm{Ra} \times 2 \mathrm{Lb}$ & 83 & obs. & 26 & 53 & 2 & 2 & \\
\hline & & & esp. & 26,65 & 52,35 & 1,35 & 2,65 & + \\
\hline & $2 R b \times 2 L b$ & 92 & obs. & 12 & 24 & 17 & 39 & \\
\hline & & & esp. & 11,35 & 24,65 & 17,65 & 38,35 & 0,089 \\
\hline & $2 R c \times 2 L b$ & 97 & obs. & 4 & 9 & 30 & 54 & \\
\hline & & & esp. & 4,56 & 8,44 & 29,44 & 54,56 & 0,122 \\
\hline \multirow[t]{6}{*}{3} & $3 \mathrm{Ra} \times 3 \mathrm{La}$ & 99 & obs. & 20 & 28 & 24 & 27 & \\
\hline & & & esp. & 21,33 & 26,67 & 22,67 & 28,33 & 0,290 \\
\hline & $3 R a \times 3 L b$ & 91 & obs. & 28 & 21 & 31 & 11 & \\
\hline & & & esp. & 31,77 & 17,23 & 27,23 & 14,77 & 2,756 \\
\hline & $3 \mathrm{Rb} \times 3 \mathrm{La}$ & 84 & obs. & 19 & 21 & 24 & 20 & \\
\hline & & & esp. & 20,48 & 19,52 & 22,52 & 21,48 & 0,418 \\
\hline \multirow[t]{2}{*}{ - } & $3 R b \times 3 L b$ & 84 & obs. & 30 & 10 & 22 & 22 & \\
\hline & & & esp. & 24,76 & 15,24 & 27,24 & 16,76 & $5,557^{\circ}$ \\
\hline
\end{tabular}


TABELA 7 - Associação de inversōes: análise intercromossômica, considerando os três pares de cromossomos. P = homozigoto para o arranjo padrão; $\mathbf{I}=$ homozigoto para a inversão; $\mathbf{H}=$ heterozigoto.

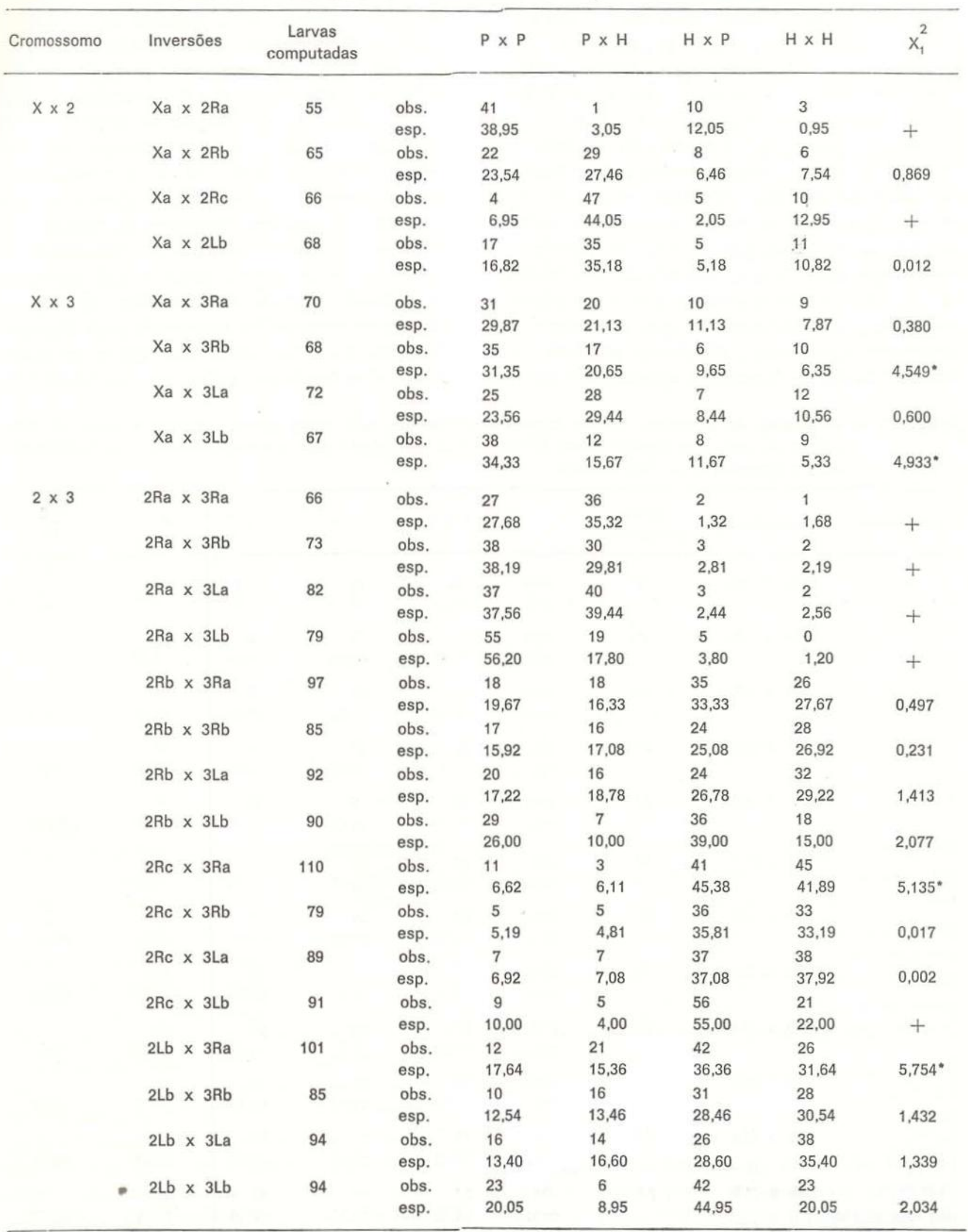

- $=P<0,05 ;+=$ qui-quadrado năo calculado. 
TABELA 8 - Análise das associações entre as regiões de despareamento e as inversões de cada braço cromossômimo. Des. $=$ regiões de despareamento; homo $=$ homozigoto para as regiões de despareamento. $P=$ homozigoto para o arranjo padrão; $\mathbf{H}=$ he terozigoto.

\begin{tabular}{|c|c|c|c|c|c|c|c|}
\hline Inversão & $\begin{array}{c}\text { Larvas } \\
\text { computadas }\end{array}$ & & $\begin{array}{c}P \\
x \\
\text { desp }\end{array}$ & $\begin{array}{c}P \\
X \\
\text { homo }\end{array}$ & $\begin{array}{c}H \\
X \\
\text { desp }\end{array}$ & $\begin{array}{c}\mathrm{H} \\
\mathrm{x} \\
\text { homo }\end{array}$ & $x_{1}^{2}$ \\
\hline $\mathrm{Xa}$ & 77 & $\begin{array}{l}\text { obs. } \\
\text { esp. }\end{array}$ & $\begin{array}{l}15 \\
17,32\end{array}$ & $\begin{array}{l}43 \\
40,68\end{array}$ & $\begin{array}{l}8 \\
5,68\end{array}$ & $\begin{array}{l}11 \\
13,32\end{array}$ & 1,795 \\
\hline $2 \mathrm{Ra}$ & 84 & $\begin{array}{l}\text { obs. } \\
\text { esp. }\end{array}$ & $\begin{array}{l}11 \\
11,28\end{array}$ & $\begin{array}{l}68 \\
67,71\end{array}$ & $\begin{array}{l}1 \\
0,72\end{array}$ & $\begin{array}{l}4 \\
4,29\end{array}$ & + \\
\hline $2 R b$ & 92 & $\begin{array}{l}\text { obs. } \\
\text { esp. }\end{array}$ & $\begin{array}{l}6 \\
5,09\end{array}$ & $\begin{array}{l}30 \\
30,91\end{array}$ & $\begin{array}{l}7 \\
7,91\end{array}$ & $\begin{array}{l}49 \\
48,09\end{array}$ & 0,311 \\
\hline $2 R c$ & 96 & $\begin{array}{l}\text { obs. } \\
\text { esp. }\end{array}$ & $\begin{array}{l}2 \\
1,25\end{array}$ & $\begin{array}{l}10 \\
10,75\end{array}$ & $\begin{array}{l}8 \\
8,75\end{array}$ & $\begin{array}{l}76 \\
75,25\end{array}$ & + \\
\hline $2 \mathrm{Lb}$ & 108 & $\begin{array}{l}\text { obs. } \\
\text { esp. }\end{array}$ & $\begin{array}{l}11 \\
7,94\end{array}$ & $\begin{array}{l}22 \\
25,06\end{array}$ & $\begin{array}{c}15 \\
18,06\end{array}$ & $\begin{array}{l}60 \\
56,94\end{array}$ & 2,236 \\
\hline
\end{tabular}

$+=$ qui-quadradio não calculado.

aproximadamente em proporção ao comprimento (Da Cunha, 1955; Dobzhansky, 1973). No entanto, em Anopheles gambiae espécie B as inversões não estão distribuídas ao acaso entre os cromossomos, ocorrendo em maior númeiro no braço $2 R$ (Coluzzi \& Kitzmiller, 1975).

A descrição de duas novas inversões para as populações da Amazônia vem reforçar o fato já mencionado por Kreutzer et al. (1972) de que a população de Anopheles darlingi do norte é mais polimórfica do que a população do sul, em relação aos diferentes tipos de inversões presentes. Alguns arranjos são mais comuns no norte, outros são mais comuns no sul.

Os autores acima citados ressaltaram que a característica mais marcante da população de Anopheles darlingi da Amazônia é a alta incidência com que ocorrem inversões no estado heterozigcto. Os autores mencionaram que cerca de $90 \%$ dos indivíduos estudados eram heterozigotos para uma ou mais inversões. O mesmo aspecto também foi verificado por nós para a população do $\mathrm{Km} 137$, porém com um grau de heterozigose ainda mais acentuado. De 32 fêmeas estudadas, nenhuma produziu descenderites homozigotos para os três pares de cromossomos sumultaneamente. O número de inversões por indivíduos, no estado heterozigoto, variou de um a sete entre os des- cendentes, sendo a média $4,13 \pm 0,13$. Indivíduos com três a cinco inversões foram os mais freqüentes, totalizando $68 \%$ da amostra estudada. Indivíduos com uma ou com sete inversões foram os menos freqüentes $(4 \%)$.

As populações da Amazônia (Manaus e do $\mathrm{Km}$ 137) são concordantes quanto ao fato de mostrarem um alto grau de heterozigose. Porém, quando são comparadas as freque ências das inversões das duas localidades, são observadas algumas variações. Para o cromossomo 2, a seqüência padrão do braço $2 \mathrm{R}$ foi o arranjo mais freqüente na população de Manaus, enquanto que no $\mathrm{Km} \mathrm{137}$, ocorreram variações em relação às três inversões. Para $2 \mathrm{Ra}$, homozigotos para o arranjo padrão foram os mais freqüentes e para $2 \mathrm{Rb}$ e $2 \mathrm{Rc}$ foram os heterozigotos. No braço 2L, o arranjo $2 \mathrm{Lb}$ foi muito freqüente no $\mathrm{Km} \mathrm{137,} \mathrm{no} \mathrm{estado} \mathrm{heterozigoto;}$ no entanto, na população de Manaus, este arranjo foi observado na proporção aproximada de $1: 2: 1$, de heterozigotos e homozigotos.

Quanto ao cromossomo 3 , as variações observadas entre as duas localidades estão relacionadas com as freqüências dos heterozigotos e homozigotos para o arranjo padrão. Os homozigotos para c arranjo das inversões são raros em ambas as localidades. Em relação ao braço $3 R$, a inversão $3 R a$, comum na população de Manaus em heterozigose $167 \%$ 
da amostra analisada), foi verificada na freqüência de $48 \%$ no Km 137. Resultados opostos foram observados para a inversão $3 R b$, que mostrou no $\mathrm{Km} 137$ alta incidência de heterozigotos, enquanto que na população de Manais foram freqüentes os homozigotos para o arranjo padrăo. Também, freqüências diferentes em relação à população de Manaus, foram observadas para as duas inversões do braço $3 \mathrm{~L}$. Para 3 La, esta inversão ocorre, no estado heterozigoto, em $50 \%$ da amostra de Manaus e em $60 \%$ do material procedente do $\mathrm{Km} 137$. A inversão $3 \mathrm{Lb}$ toi verificada, em heterozigose, em apenas $32 \%$ do material do $\mathrm{Km} 137$, enquanto que foi freqüente também em heterozigose em Manaus.

As variações acima mencionadas podem ser interpretadas como respostas seletivas diferentes das variantes genéticas, que não são igualmente adaptativas para os vários nichos ecológicos explorados pela espécie. Variações nas frequeências de arranjos gênicos, ao longo da área de distribuição de uma determinada espécie, têm sido extensivamente observadas em Drosophila. Diferenças, quer qualitativas, quer quantitativas, foram verificadas em $D$. guaramunu (Brncic, 1953; Salzano, 1955), D. pseudocbscura e D. persimilis (Dobzhansky, 1956: Anderson et al., 1975), D. robusta (Carson, 1958), D. athabasca (Miller \& Volker, 1972), D. prosaltans (Bicudo, 1973; Bicudo et al., 1978), D. subobscura (Krimbas \& Loukas, 1980) e outras. No gênero Anopheles, diferen- ças quanto ao polimorfismo cromossômico têm sido utilizadas para caracterização de espécies como, por exemplo, no complexo A. maculipennis da Europa, complexo A. gambiae da África. Em A. albitarsis, Kreutzer et al. (1976) identificaram três populações dessa espécie que diferem quanto aos arranjos gênicos.

Além das freqüências das inversões, as duas localidades da Amazônia também mostram diferenciação quanto aos arranjos presentes. As inversões $2 R$ d e $3 R$ c não foram detectadas por Kreutzer et. al. (1972), quando da análise da população de Manaus. Além dos arranjos, também as três regiões de despareamento não foram mencionadas por aqueles autores.

O nível de diferenciação torna-se maior quando as populações da Amazônia são comparadas com as populações do sul. Kreutzer et al. (1972) verificaram reduzido polimorfismo cromossômico na população do sul e, aparentemente, alguns arranjos foram fixados. Algumas inversões, que foram comuns no estado heterozigoto nas populações do norte. foram observadas apenas na forma homozigota no sul. Também, algumas inversöes que foram freqüentes no norte, aparentemente estão ausentes no sul. As inversões $2 \mathrm{Rd}$ e $3 \mathrm{Rc}$, descritas neste trabalho, assim como as três regiões de despareamento, permitem ampliar ainda mais o nível de diferericiação entre as duas populações.

Os dados acima mencionados estão em acordo com a hipótese de $\mathrm{Da}$ Cunha et al.

TABELA 9 - Valores observados e esperados nos testes de associaçäo entre as regiöes de despareamento dos cromossomos X e 2. Desp = regiōes de despareamento; homo - homozigoto para as regiões de despareamento.

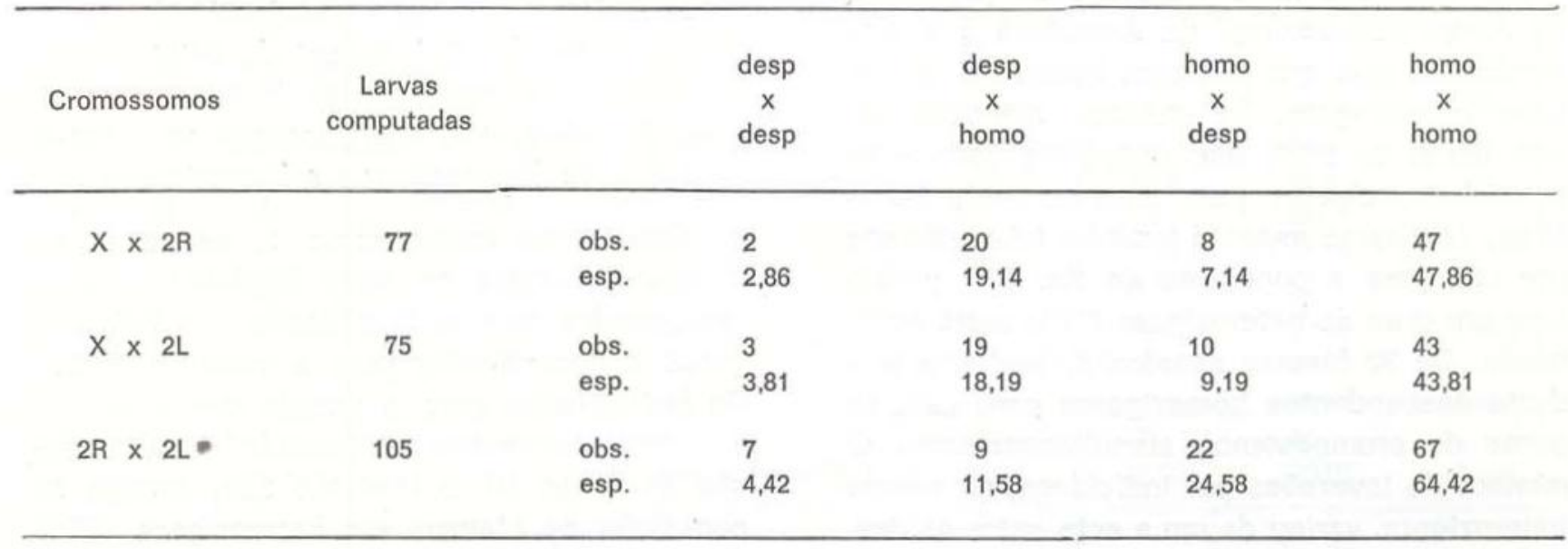


(1950) e Da Cunha e Dobzhansky (1954) de que a quantidade de polimorfismo cromossômico tende a ser proporcional às variedades de habitats explorados pela espécie, na área de distribuição geográfica. Esses autores evidenciaram que populações de Drosophila willistoni da área marginal tendem a ser menos polimórficas do que populações da área central de distribuição, ecologicamente mais diversificada. A população de Anopheles darlingi do Amazonas, ccuparıdo uma posição mais central da área de distribuição, apresenta elevado polimortismo; $\unlhd$ a população de Araraquara, estando mais próxima da área marginal, aparentemente fixou determinados ararnjos com reduzido polimorfismo.

A observação das freqüências dos arranjos das inversões possibilita verificar a ocorrência de heterozigotos em freqüências superiores a $50 \%$ e os números são estatisticamente significativos, na maioria dos casos. Estes resultados são indicativos de que em populações naturais de Anopheles darlingi, os heterozigotos apresentam valor adaptativo superior, ocorrendo seleção contra os homozigotos. A seleção natural estabeleceria então uma situação de polimorfismo balanceado. Estudos em populações naturais de Drosophila têm proporcionado evidências de que o polimorfismo cromossômicn é usualmente balanceado. Dobzhansky \& Pálovsky (1958) estudando populações de Drosophila willistoni, D. paulistorum e D. tropicalis verificaram que em algumas populações dessas espécies da América do Sul, mais da metade dos indivíduos encontrados na natureza são heterozigotos para certas inversões. No presente trabalho, embora os dadcs apresentados resultem da análise de 118 indivíduos que não foram coletados diretamente da natureza, mas são diescendentes $F_{1}$ de 32 fêmeas inseminadas na natureza, constituem elementos indicativos de que em populações naturais de Anopheles darlingi poderia ocorrer uma estrutura genética semelhante à verificada por Dobzhansky \& Pavlovsky para as três espécies de Drosophila acima citadas.

A amostra de Anopheles ciarlingi estudada neste trabalho foi obtida no $\mathrm{Km} \mathrm{137}$, em um ponto localizado na margem da rodovia. Os espécimes coletados vinham se alimentar nas iscas que ai permaneciam e, provavelmente, eram procedentes de diferentes habitats da mata das proximidades, considerando-se que a espécie apresenta um raio de vôo de cerca de 2.000 metros (Deane, 1947). Como as florestas tropicais apresentam grande heterogeneidade ambiental dentro de pequenos territórios, é razoável admitir que nossa amostra seja formada de indivíduos procedentes de habitats diversos. Como ocorrem freqüências elevadas de heterozigotos para a maioria das inversões, os resultados são indicativos de uma adaptabilidade maior dos heterozigotos em relação à heterogeneidade ambiental. Sugerem também que os homozigotos para o arranjo padrão são superiores em relação aos homozigotos para o arranjo das inversões, pois estes ocorrem em freqüências sempre muito baixas.

O's testes para associação de inversões evidenciaram cinco casos em que as inversões não se distribuem ao acaso, sendo uma intracromossômica (tabela 6) e as restantes intercromossômicas (tabela 7). Em relação à primeira, trata-se de uma interação entre inversões localizadas em braços diferentes e que estão separadas por sete regiões cromossômicas (fig. 2). Considerando que este segmento cromossômico seja suficientemente grande para possibilitar permutação entre elas, podemos admitir que as inversões $3 R$ e $3 \mathrm{Lb}$ estão em associação, pois todas as demais, dentro de cada braço cromossômico, apresentam distâncias menores e se distribuem ao acaso. A divergência favcrece os indivíduos heterozigotos para inversões em ambos os braços e indivíduos homozigotos para o arranjo padrão, também para ambos os braços. Nos casos em que foram verificadas associações intercromossômicas, excetuando-se a combinaçăo $2 \mathrm{Lb} \times 3 \mathrm{Ra}$, a divergência também favorece o duplo heterozigoto e o duplo homozigoto para o arranjo padrão. Este fato é indicativo de que provavelmente os mesmos processos seletivos que ocorrem ao nívei das interações intracromossômicas, estariam ocorrendo também ao nível das intercromossômicas. Para a combinação $2 \mathrm{Lb} \times 3 \mathrm{Ra} 0$ fenômeno seria oposto, pois o desvio favorece as combinações homozigotas para o arranjo padrão de $2 \mathrm{Lb}$ e heterozigotas para $3 \mathrm{Ra}$ e a forma inversa. 
Estudos de asssociação de arranjos gênicos em espécies de Drosophila têm mostrado que as inversões em associação (cis) e em repulsão (trans) ocorrem em freqüências diferentes, conforme a espécie considerada $\in$ a localidacie. $\operatorname{Em} D$. guaramunu arranjos em associação são favorecidos enquanto que em repulsão são selecionados contra (Levitam \& Salzano, 1959) . Em D. robusta ocorre fenômeno inverso, sendo favorecidos determinados arranjos em repulsão (Levitan, 1958). Bicudo et al. (1978) evidenciaram que em duas localidades brasileiras, quatro arranjos de $D$. prosaltans apresentam valores adaptativos semelhantes quando os braços cromossômicos são considerados isoladamente, mas valores adaptativos opostos quando os braços IIL e IIR são considerados simultaneamente. Em uma localidade predominou arranjo em repulsão e na outra em associação. Em Anopheles darlingi, os efeitos das interações intra e intercromossômicas são desconhecidos. Contudo, como ocorre em espécies de Drosophila, provavelmente tratam-se de interações adaptativas, nas quais a seieção favorece a reunião de arranjos independentes. Uma análise pormenorizada em $A$. darlingi das frequências dos arranjos em associação e em repu'são e inclusive incluindo dados de outras regiões brasileiras, será objeto de um próximo trabalho.

Ainda um ponto a ser destacado em relação às associações intercromossômicas e mesmo intracromossômicas, refere-se à recombinação. Extensivos estudos em espécies de Drosophila evidenciaram que as inversões, no estado heterozigoto, estendem seus efeitos sobre a recombinação também às regiões adjacentes ao segmento invertido no mesmo cromossomo e, sob determinadias circunstâncias, apresentam efeitos ainda sobre a recombinação em outros cromossomos (Morgan et al., 1930; Sturtevant \& Beadle, 1936; Dobzhansky \& Epling, 1948; Schuitz \& Redfield, 1951; Carson, 1953; Eugenev, 1970). Os dados apresentados neste trabalho não abrangem esse aspecto. No entanto, considerando que a população estudada apresenta altas freqüências de indivíduos no estado heterozigoto $(58 \%$ da amostra apresentaram de três a cinco inversões), é razoável admitir que estas associações devem ter algum efeito sobre a recombinação intra e intercromossômica. Neste caso, os efeitos devem ser adaptativos, considerando a alta incidência com que ocorrem indivíduos com inversões no estado heterozigoto.

Um outro aspecto ainda a ser discutido refere-se às três regiões de despareamento. Eugenev (1971), estudando o pareamento cromossômico entre híbridos interespecíficos de Drosophila virilis, D. texana e $D$. littoralis, verificcu que o mesmo não resulta de interação genética especifica no hibrido, mas depende das propriedades dos loci dos próprios cromossomos. Segundo o autor, a extensão em que a atração entre os homólogos é diminuída em híbridos interespecíficos, depende, provavelmente, da quantidade de trocas moleculares que ocorreu nos cromossomos das espécies relacionadas. Admitindo-se que as três regiões de ciespareamento mencionadas representam segmentos onde tenha ocorrido diferenciação genética, essas regiões evidenciam a existência de duas formas cromossômicas na população - a normal e a com diferenciação genética.

Dentre as regiões de despareamento, tornase particularmente importante, o segmento localizado no cromossomo $X$, considerando-se que $\cap$ mesmo pode ser elemento indicativo de um processo de especiaçäo em desenvolvimento. Conforme os dados da literatura, o cromossomo $\mathrm{X}$, durante o processo evolutivo do gênero Anopheles, tem sido o mais sensivel a rearranjos (Kitzmiller, 1977). As espécies de Anopheles, nos diferentes grupos, podem ser identificadas com base no padrão de bandas deste cromossomo que apresenta, na maioria dos casos, seqüência única para cada espécie. Dentre os mecanismos que levariam à fixação de rearranjos neste cromossomo, Kitzmiler (1977) sugeriu que o padrão atual poderia ter resultado de inversões que foram freqüentes e que se fixaram durante o processo evolutivo, talvez em período de rápida adaptação para uma variedade de ambiente. As três regiões de despareamento representam a nosso ver, formas alternativas de constituição genética e poderão ter papel no processo de adaptação da população aos diferentes habitats $\in \mathrm{m}$ que a espécie ocorre. 
A análise do polimorfismo cromossômico de Anopheles darlingi proporciona dados relacionados a aspectos evolutivos e também dados que podem ser correlacionados à capacidade vetora da espécie. A ocorrência de doze rearranjos diferentes possibilita um número elevado de combinações cromossômicas que é ampliado ainda mais se forem consideradas também as três regiões de despareamento. Como a freqüência de espécimes de Anopheles darlingi infectados por Plasmodium em populações naturais é muito baixa, este fato sugere que alguns indivíduos podem não ser susceptiveis de infecção. Desta forma, o conhecimento da estrutura citogenética da população, correlacionada ao grau de susceptibilidade à infecções por Plasmodium, poderá constituir-se em um parâmetro fundamental para avaliação da capacidade vetora de uma dada população de Anopheles clarlingi.

\section{Agradecimentos}

Somos gratos ao Professor Doutor Warwick E. Kerr pela oportunidade de realização deste trabalho e pelo auxílio nas várias etapas do seu desenvolvimento, quer na análise, quer na leitura do manuscrito. A Professora Doutora Hermione E. M. de C. Bicudo pela leitura do manuscrito e sugestões. Aos Professores Doutores Paulo S. Martins e Woodruff Benson pelas valiosas críticas e contribuições. A Sra. Elcy I. Santos e ao Sr. José M. Correia pelos serviços técnicos.

O primeiro autor é grato ainda ao Professor Kerr por ter proporcionado a oportunidade de continuar os estudos citogenéticos de Anopheles darlingi, iniciados por Mohammad G. Rabbani e assim conhecer o valor desse cientista, cuja dedicação e cuidado possibilitou a reconstituição da história iniciada em 22 de janeiro de 1976, quando chegou à Amazônia, no INPA em Manaus.

\section{SUMMARY}

The chromosomic polymorphism of Anopheles darlingi, whose sample was obtained in Highway BR-174 (Manaus/Boa Vista), was here analyzed. Two new independent inversions were described, and the number of rearrangements was raised to twelve. Three asynapsed regions were also described, being one in chromosome $X$ and two in chromosome 2. There was a high occurence of inversions at the heterozygote state and the medium number per individual was high $(4,13 \pm$ $0,13)$. The higher and meaningful frequencies of heterozygote indicated their larger adaptability to the enviromental heterogeneity. The tests for the association of inversions showed the occurrence of an intrachromosomic association (arms $3 R$ and $3 \mathrm{~L}$ ) and four interchromosomic ones (chromosomes X-3 and 2-3).

The data of the Anopheles darlingi chromosomic polymorphism support the hypothesis that the central populations of a geographic area are more polymorphic than the marginal populations. The $A$. darlingi populations of Amazônia are highly polymorphic as compared to the southern ones, where certain arrangements with reduce polymorphism were determined.

\section{REFERENCIAS BIBLIOGRÁFICAS}

ANDERSON, W.; DOBZHANSKY, Th.; PAVLOVSKY, O.; POWELL, J.R. \& YARDLEY, D.

1975 - Genetics of natural populations. XLII. Three decades of genetic change in Drosophila pseudoobscura. Evolution, 29: 24-36.

BICUDO, H.E.M.C.

1973 - Chromosomal polymorphism in the saltans group of Drosophila. I. The saltans subgroup. Genetica, 44: 520-552.

BICUDO, H.E.M.C.; HOSAKI, M.K.; MACHADA, J. \& MARQUES, M.C.N.

1978 - Chromosomal polymorphism in the saltans group of Drosophila. II Further study on D. prosaltans. Genetica, 48: 5-15.

BRNCIC, D.

1953 - Chromosomal variation in natural populations of Drosophila guaramunu. Z . indukt. Abstamm.-u, Vererblehre, 85: 1-11.

CARSON, H.L.

1953 - The effects of inversions on crossing over in Drosophila robusta. Genetics, 38: 168186.

1958 - The population genetics of Drosophila robusta. Adv. Genet., 9: 1-40.

CARSON, H.L.; CLAYTON, F.E. \& STALKER, H.D.

1967 - Karyotype stability and speciation in Hawaiian Drosophila. Proc. Nat. Acad. Sci. (Wash), 57, 1280.

COLUZZI, M.; DI DECO, M. \& CANCRINI, G.

1973 - Chromosomal inversions in Anopheles stephensi. Parassitologia, 15: 129.

COLUZZI, M. \& KITZMILLER, J.B.

1975 - Anopheline mosquitoes. In: Handbook of Genetics (R.C. King. ed.) vol. 3, Chapter 12, pp. 289-309. New York. Plenum. 
DA CUNHA, A.B.

1955 - Sobre duas raças de Drosophila neocardini Streisinger. Rev. Brasil. Biol., 15: 117-125.

DA CUNHA, A.B.; BURLA, H. \& DOBZHANSKY, Th. 1950 - Adaptive chromosomal polymorphism in Drosophila willistoni. Evolution, 4 212.235.

DA CUNHA, A.B. \& DOBZHANSKY, Th.

1954 - A further study of chromosomal polymorphism in Drosophila willistoni in its relation to the environmen. Evolution, 8, 119-134.

DEANE, L.M.

1947 - Observações sobre a malária na Amazônia brasileira. Rev. Serv. Esp. Saúde Pub., 1: 3.60.

DOBZHANSKY, Th.

1956 - Genetics of natural populations XXV. Genetic changes in populations of Drosophila pseudoobscura and Drosophila persimilis in some localities of California. Evolution, 10: 82-92.

1973 - Genética do Processo Evolutivo. São Paulo, EDUSP.

DOBZHANSKY, Th. \& EPLING, C.

1948 - The suppression of crossing over in inversion heterozigotes of Drosophila pseudoobscura. Proc. Nat. Acad. Sci., 34: 137-141.

DOBZHANSKY, Th. \& PAVLOVISKY, $O$.

1958 - Interracial hybridization and breakdown of coadapeted gene complexes in Drosophila paulistorum and Drosophila willistoni. Proc. Natl. Acad. Sci., 44: 622-629.

EUGENEV, M.B.

1970 - The interchromosomal effect of inversions on crossing over in the interspecific D. virilus $\times$ D. texana hybrids Genetika (USSR), 2: $68-72$.

1971 - The pattern of polytene chromosome conjugation and crossing-over in interspecific hybrids of Drosophila. Theoret. Appl. Genetics, 41: 249-254.

FERRARONI, J.J. \& HAYES, J.

1979 - Aspectos epidemiológicos da malária no Amazonas. Acta Amazonica, 9: 471-479.

FERRARONI, J.J.; WAKI, S. \& SUZUKY, M.

1977 - Resistência do Plasmodium falciparum às cloroquinas no Estado do Amazonas detectada pelo método in vitro. Acta Amazonica, 7: 147-148.

FERREIRA, E.

1964 - Distribuição geográfica dos anofelinos no Brasil e sua relação com o estado atual da erradicação da malária. Rev. Bras. Malariol. D. Tropicais, 16: $329-348$.

FORATTINI, O.P.

1962 - Entomologia Médica. 1: volume. São Paulo, Editora Univ. São Paulo.
FRENCH, W.L.; BAKER, R.H. \& KITZMILLER, J.B.

1962 - Preparation of mosquito chromosomes. Mosquito News, 22: 377-383.

GUEDES, A.S.; AMORIM, E.M. \& SCHROBBER, G.

1957 - Análise dos cromossomos salivares em anofelinos brasileiros. Rev. Bras. Malariol. D. Tropicais, 9: 247-250.

HAYES, J. \& CHARLWOOD, D.C.

1977 - O Anopheles darlingi evita o DDT numa área de malária resistente a drojas. Acta Amazonica, 7: 289.

KITZMILLER, J.B.

1976 - Genetics, cytogenetics and evolution of mosquitoes. Advances in Genetics, 18: 315-433.

1977 - Chromosomal differences among species of Anopheles mosquitoes. Mosquito Systematics, 9: 112-122.

KREUTZER, R.D.; KITZMILLER, J.B. \& FERREIRA, E.

1972 - Inversion polymorphism in the salivary gland chromosomes of Anopheles darlingi Root. Mosquito News, 32: 355-365.

KREUTZER, R.D.; KITZMILLER, J.B. \& RABBANI, M.G.

1976 - Cytogenetically distinguishable sympatric and allopatric populations of the mosquito Anopheles albitarsis. Acta Amazonica, 6 (4): 473-481.

KRIMBAS, C.B. \& LOUKAS, M.

1980 - The inversion polymorphism of Drosophila subobscura. Evolutionary Biology, 12: 163234.

LEVITAN, M.

1958 - Non-random associations of inversions. Cold Spring Harbor Symp. Quant. Biol., 23: 251268.

LEVITAN, M. \& SALZANO, F.M.

1959 - Studies of linkage in populations. III. An association of linked inversions in Drosophila guaramunu. Heredity, 13: 243-248.

MILLER, D.D. \& VOLKER, R.A.

1972 - Salivary gland chromosome variantion in the Drosophila affinis sub-group. V. The B and $\mathrm{E}$ chromosomes of "Western" and "Eastern" Drosophila athabasca. J. Hered. 63: 2-10.

MORGAN, T.H.; BRIDGES, C.B. \& SCHULTZ, J.

1930 - The constitution of the germinal material in relation to heredity. Yearb. Carneg. Inst. Wash., 29: 352-359.

PESSOA, S.B. \& MARTINS, A.V.

1978 - Parasitologia Médica. Rio de Janeiro, Editora Guanabara Koogan S.A.

RACHOU, R.G.

1958 - Algumas manifestações de resistência de comportamento de insetos aos inseticidas no Brasil. Rev. Bras. Malariol. D. Tropicais, 10: $277-290$. 
SALZANO, F.M.

1955 - Chromosomal polymorphism in two species of the guarani group of Drosophila. Chromosoma, 7: 39-50.

SCHREIBER, G. \& GUEDES, A.S.

1960 - Perspectivas citológicas na sistemática dos anofelinos (S.G. Nyssorhynchus). Rev. Bras. Malariol. D. Tropicais, 12: 355-358.

1961 - Cytological aspects of the taxonomy of anophelinos (subgenus Nyssorhynchus). Bull. WLD. Hlth. Org., 24: 657-658.

SCHULTZ, J. \& REDFIELD, $\mathrm{H}$.

1951 - Interchromosomal effects on crossing over in Drosophila. Cold Spring Harbor Symp. Quant. Biol., 16: 175-197.
STURTEVANT, A.H. \& BEADLE, G.W.

1936 - The relations of inversions in the X-chromosome of Drosophila melanogaster to crossing over and disjunction. Genetics, 21: $554-604$.

WASSERMAN, M.

1963 - Cytology and phylogeny of Drosophila. Amer. Nat., 896: 333

WHITE, G.B.

1974 - Biological effects of intraspecific chromosomal polymorphism in malaria vector populations. Bull Wld Hlth Org., 50: 299-306.

(Aceito para publicação em $05 / 08 / 81$ ) 